
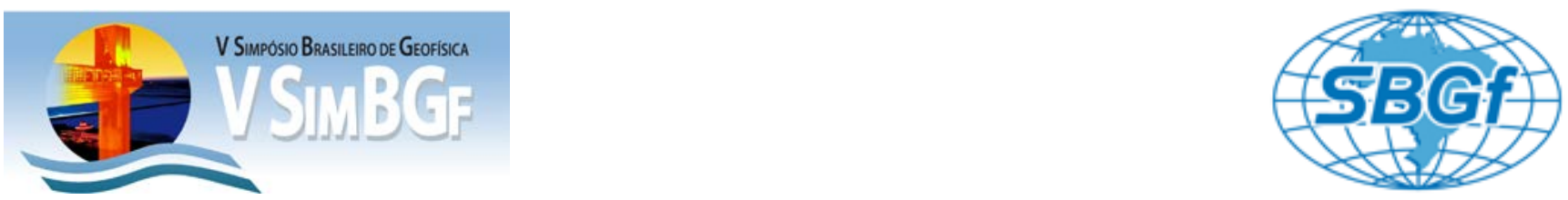

\title{
Levantamento magnetométrico em ocorrência de cobre, na Colônia Santa Bárbara, município de Caçapava do Sul, RS. - resultados preliminares
}

Leticia Borges*, Kathlem Melo, Renata Pereira, Lucas Motta e Maximilian Fries, Universidade Federal do Pampa, Centro de Ciências Exatas e da Terra - Campus Caçapava do Sul

Copyright 2012, SBGf - Sociedade Brasileira de Geofísica

Este texto foi preparado para a apresentação no $V$ Simpósio Brasileiro de Geofísica, Salvador, 27 a 29 de novembro de 2012. Seu conteúdo foi revisado pelo Comitê Técnico do $V$ SimBGf, mas não necessariamente representa a opinião da SBGf ou de seus associados. É proibida a reprodução total ou parcial deste material para propósitos comerciais sem prévia autorização da SBGf.

\section{Abstract}

The region of South Caçapava recognized by student and researchers as a Mineral province, has for decades been studied by different methods within the field of geosciences.. The aim proposal in this study is to achieve an understanding and analysis within the mineral exploration and the geological and structural framework in the known area named Colonia Santa Barbara. The integrate use of geophysical method magnetometry integrated with geological survey and previous studies helps to provide information to confirm or refute theories about the genesis and distribution of the ore and its correlation with the surrounding rocks. This study presents a preliminary aproach and result obtained by a terrestrial magnetic survey in detaile scale.

\section{Introdução e objetivos}

O método geofísico da magnetometria é usado para trabalhos de prospecção e exploração de petróleo e de minérios. É um método eficaz também na análise quantitativa e qualitativa de estruturas, litologias e descontinuidades assim como seus limites. $\mathrm{Na}$ prospecção mineral apresenta resultados satisfatórios em depósitos de sulfetos disseminados em rochas que contenham uma grande quantidade de minerais magnéticos que geram significantes anomalias, como por exemplo, depósitos de cobre, níquel, zinco, chumbo, ferro, titânio etc.

O objetivo principal desse trabalho é realizar um levantamento magnetométrico terrestre em escala de detalhe na localidade conhecida como Colônia Santa Bárbara situada no município de Caçapava, Estado do Rio Grande do Sul. Propõe identificar respostas anômalas obtidas pelas litologias, estruturas e eventuais mineralizações de cobre presentes na área. O método geofísico da magnetometria terrestre juntamente com informações geológico-estruturais já existentes da área, fornece subsídios para modelos geofísicos/geológicos que podem ser correlacionados a estudos da gênese, concentração e disseminação das mineralizações na área.
As principais fases de desenvolvimento deste estudo preliminar são:

- Levantamento bibliográfico, digitalização e geração de mapas;

- Levantamento magnetométrico terrestre e correção diurna dos dados;

- Geração de uma base de dados e mapas geofísicos;

- Interpretaçao preliminar do mapa de isovalores com os valores magnetométricos de campo total;

\section{Localização da área e Contexto Geológico}

A área da ocorrência cuprífera localizada na Colônia Santa Bárbara situa-se no município de Caçapava do Sul, podendo ser acessada por uma estrada municipal. O município de Caçapava do Sul dista a aproximadamente $250 \mathrm{Km}$ da capital Porto Alegre. (Figura 1)

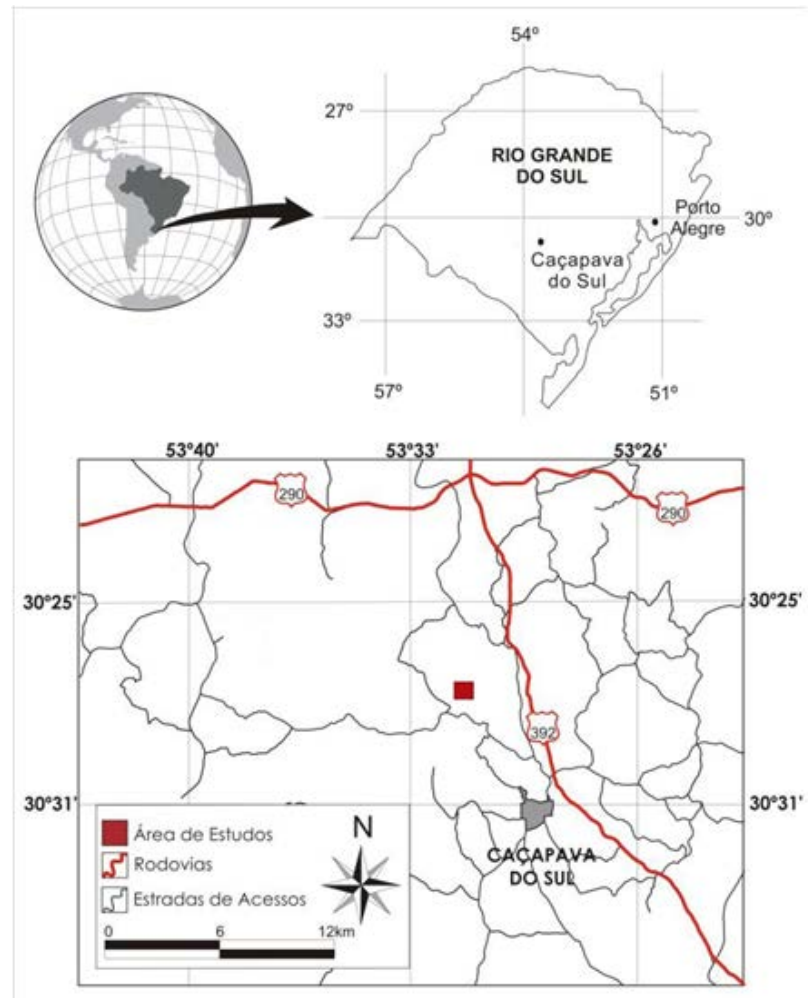

Figura 1 - Mapa de localização da área de estudo com as principais rodovias e estradas vicinais. 
A região da Colônia Santa Bárbara (Figura 2) é caracterizada por coberturas vulcano-sedimentares pertencentes à formação Hilário, que se sobrepõem discordantemente às unidades metamórficas do Escudo Sul-Rio-Grandense.
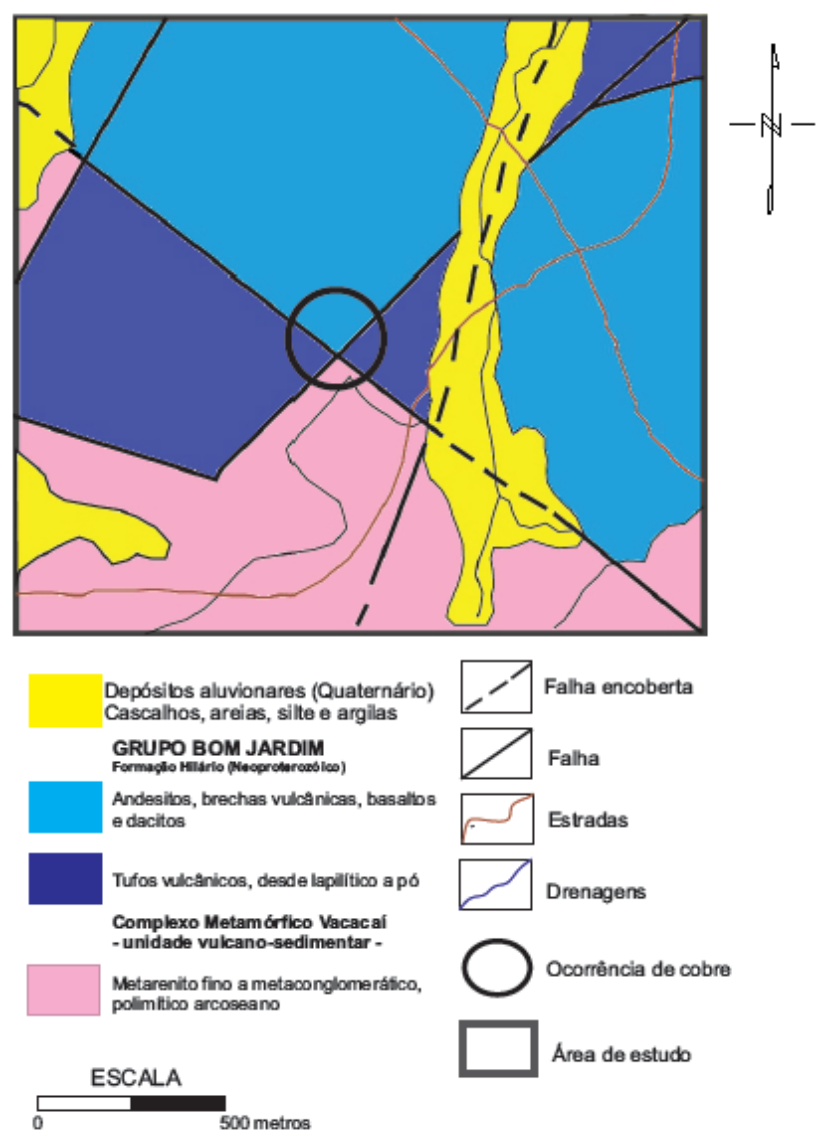

Figura 2 - Mapa geológico da região de Caçapava do Sul e principais unidades aflorantes na região (Modificado de Porcher, 1995).

As rochas reunidas no Grupo Bom Jardim são representadas na área de estudos pela Formação Hilário, representada por depósitos de natureza vulcânica, sejam eles derrames, rochas subvulcânicas ou vulcanoclásticas, estas tanto de natureza piroclástica quanto epiclástica, relacionadas ao magmatismo intermediário a básico, de afinidade shoshonítica (NARDI \& LIMA, 1985). O Cinturão Metamórfico Vacacaí compõe a porção relacionada a um sistema de arco de ilhas representado por rochas vulcânicas e vulcanoclásticas metamorfizadas, de composição andesítica e dacítica, e tufos intermediários, além de xistos pelíticos e psamíticos.

\section{Metodologia}

Foram adquiridas até o presente momento um total de 255 estações magnetométricas terrestres com medidas realizadas com um magnetometro de precessão de prótons modelo GSM 19 da GEM Systems inc. Para o georeferenciamento (coordenadas $X$ e $Y$ ) empregou-se um GPS de mão. As estações possuem um espaçamento de 20 metros cada e nesta etapa preliminar, foram feitos em perfis pré-determinados, perpendiculares às estruturas reconhecidas em superfície. Foi gerado inicialmente um mapa magnetométrico com os isovalores de campo anômalo total a partir um grid com células de $10 \times 10$ metros. Para a elaboração do grid foi adotado o método da mínima curvatura.

Os isovalores gerados a partir do grid permitem a geração de um mapa de cores sombreado com as respectivas anomalias magnéticas apresentadas. A geração da base de dados com as estações magnetométricas, coordenadas, dados das anomalias magnéticas e mapas foram elaborados por rotinas próprias no software OASIS/MONTAJ comercializado pela Geosoft Inc.

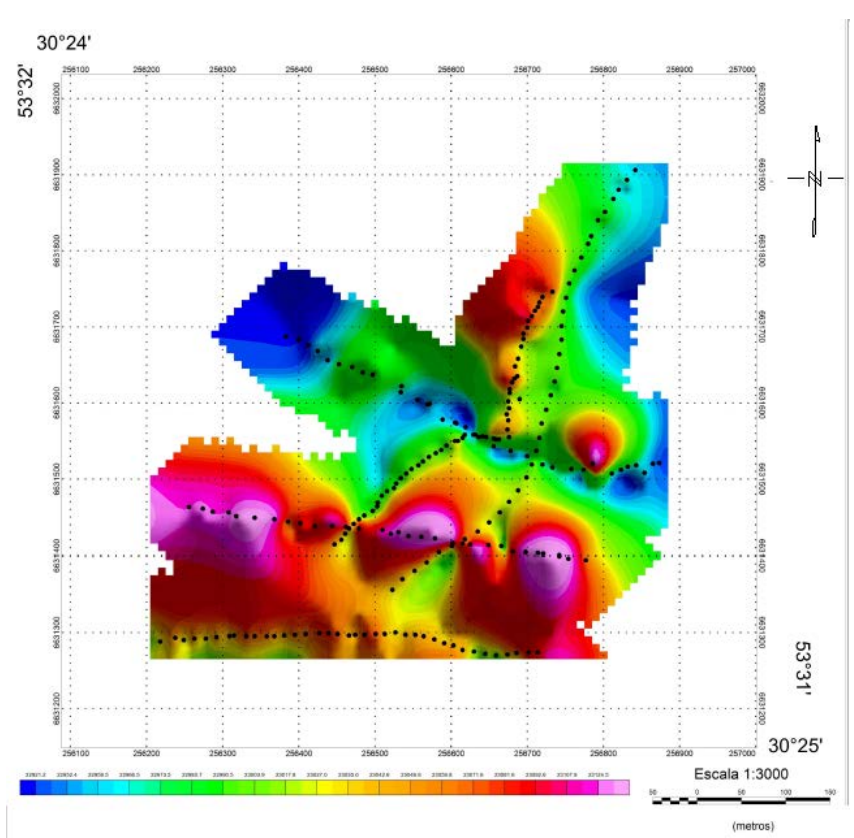

Figura 1 - Mapa de contorno sombreado e de pontos dos valores magnéticos de campo total.

\section{Discussão e Conclusões}

Os perfis magnetométricos preliminarmente realizados servem como abordagem inicial para verificação do comportamento das respostas geofísicas obtidas (contrastes de susceptibilidade magnética) As anomalias magnéticas de campo total, possuem gradientes que variam de $22.957 \mathrm{nT}$ a $23.183 \mathrm{nT}(226 \mathrm{nT})$ observadas ao longo de toda a área (perfis perpendiculares). A análise do mapa de campo total permite diferenciar as anomalias 
magnéticas correlacionáveis as altas susceptibilidades magnéticas dos materiais (mineralizações, litologia e estruturas) oriundas de fontes rasas e profundas. Há, também, visível contraste na porção sul da área alinhada em uma direção E-W. Técnicas de processamento posteriormente aplicadas aos dados magnetométricos permitirão um melhor entendimento, visualização e análise das anomalias, assim como a correlação com estruturas e litologias reconhecidas em superfície.

\section{Agradecimentos}

Os autores agradecem o auxílio prestado pelo geólogo MSc Marcelo Lusa durante as aquisições magnetométricas e reconhecimento geológico de campo na área. A UNIPAMPA - Campus Caçapava do Sul, que disponibilizou veículos e os equipamentos para a execução do trabalho. E ao professor doutor Maximilian Fries que possibilitou o conhecimento e informações necessárias para realização deste trabalho.

\section{Referências}

GEM SYSTEMS - GSM 19 v 7.0 Instruction manual, http://www.gemsys.ca.

GEOSOFT INCORPORATED. 1999. Montaj MAGMAP filtering; 2 - D frequency domain of potential field data extension for Oasis Montaj v.6.1. Toronto, Ontario, Canadá.

FRIES, M. Escudo dos altos estruturais de Pitanga, Artemis, Pau D'Alho e Jibóia (flanco nordeste da Bacia Sedimentar do Paraná), através do método geofísico da Gravimetria e Magnetometria terrestre. Tese de Doutorado, (2008), 262p., Universidade Estadual Paulista.

NARDI, Lauro Valentim Stoll.; BITENCOURT, Maria de Fatima Aparecida Saraiva Geologia, Petrologia e Geoquímica do Complexo Granítico de Caçapava do Sul, RS. Revista Brasileira de Geociências, v. 19, n. 2, p. 153-169, 1989.

PORCHER, Carlos Alfredo et al. Programa Levantamentos Geológicos Básicos do Brasil. Folha Passo do salsinho, Folha SH.22-Y-A-I-4. Estado do Rio Grande do Sul. Escala 1:50.000. Brasília: CPRM, 1995. $372 \mathrm{p}$.

SCHWEIG, C.B., Caracterização Geoelétrica da Ocorrência de Cobre Colônia de Santa Bárbara, Município de Caçapava do Sul (RS). 2010. Trabalho de Graduação, 77p., Universidade Federal do Pampa. 